\title{
Study on FWD applying to layered control compaction quality
}

\author{
Limin Yang ${ }^{1, a}$, Yushan $\mathrm{Ye}^{2, \mathrm{~b}}$, Jiangwei Wang ${ }^{3, \mathrm{c}}$, Chengchao Guo ${ }^{4, \mathrm{~d} *}$ \\ ${ }^{1,2,3}$ China Construction Seventh Engineering Division, Corp.Ltd. \\ NO.108 of East of City Road Zhengzhou Henan China. \\ ${ }^{4}$ Zhengzhou University. NO.100 of Science Road Zhengzhou Henan China.

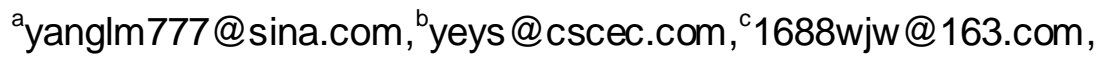 \\ 'wangchench@163.com
}

Keywords: FWD, deflection basin index, compaction

\begin{abstract}
Treating soil compaction is the key to its construction quality control, but now its compaction evaluating indicator does not match with design specification in China, which makes design and construction control having disjointed phenomenon. Based on the deflections tested by FWD, the relationship between pavement surface deflections and its structure deformation is analyzed in this paper, and the result shows that the compaction of the load layer can be reflected by three deflections which are most close to the bearing plate. Combining with the field tests, the relationship between the deflections and compaction is further studied, and good correlation between deflection basin index and compaction is found, so the evaluating index of compaction is put forward. Thus, the layering monitor of construction quality is tried to develop in roller compaction process, which provides an idea for the soil quality control.
\end{abstract}

\section{Introduction}

In subgrade and subbase construction process, the compaction of filling materials is the key to quality control. The cutting ring method, the sand replacement method, the wax enveloped method, the water-filling method, the core-drilling method, and the nuclear density meter method and so on are the common methods to detect dense degree of compacted soil. These methods theoretically are based on the ratio between dry density (namely measured dry density) of compacted soil and maximum dry density of indoor standard compaction test to determine soil compaction degree. In addition, compaction test can damage the subgrade and subbase structural uniformity at some extent (Guo and Wang, 2008).

Although compaction has a certain relationship with the bearing capacity, it can not evaluate soil support performance, and only reflect the dense degree of compacted layer. Pavement engineers have familiared with some measurement methods to evaluate soil bearing capacity, namely in-situ CBR test, plate bearing test and portable falling weight deflectometer (PFWD) test (Guo and Wang,2008; Wang and Guo,2009 \& Yoshio and Osamu,2007). PFWD measurement is one of common evaluation methods for sub grade and subbase strength, but its applying load impact is limit, and can not always reflect the compacted layer stiffness. Moreover, in some case compactness even exceeds $100 \%$, or decays with age, which makes it difficult to judge its degree of compaction (Wang et al, 2007 \& Zhang et al,2007). As one of the important nondestructive testing tools, FWD has been more and more popularly used in highway engineering, whose measured deflections contain abound information, and some results show that the deflection basin indexes calculated from deflections at different positions can express different layer structural conditions of pavement 
(Y. R.et al, 2001). Hence, combining with field measured data, the relationship between compactness and central deflection and deflection basin index has been tried to study to layered control compactness quality in the paper.

\section{Relationship of compactness and central deflection}

Central deflection is the response of whole structure layer under applied load, and in many cases is a kind of evaluating means of bearing capacity, and is also often taken as a control index (Guo and Wang,2008). However, compactness means dense degree of the filled materials with a certain thickness under the repeated roll, and it is generally considered that the compacted layer reaching certain compactness can bear the corresponding designed load.

A pavement structure, whose treated layer is $20 \mathrm{~cm}$ thickness $4 \%$ cement soil, cushion layer is 20 $\mathrm{cm}$ thickness $6 \%$ cement soil, and subbase is $20 \mathrm{~cm}$ thickness $12 \%$ cement and lime stabilized soil, and corresponding control compactness all is $95 \%$. After construction, the deflection data measured by FWD and the sand replacement method are respectively carried out on treated layer, cushion layer, and subbase of the test section.

The curves of compactness and measured central deflection of different positions at treated layer, cushion layer, and subbase are showed in Fig 1. It is clear that there is no good correlation between compactness and maximum deflection, so only the maximum deflection can not reflect the degree of compaction of the compacted layer.
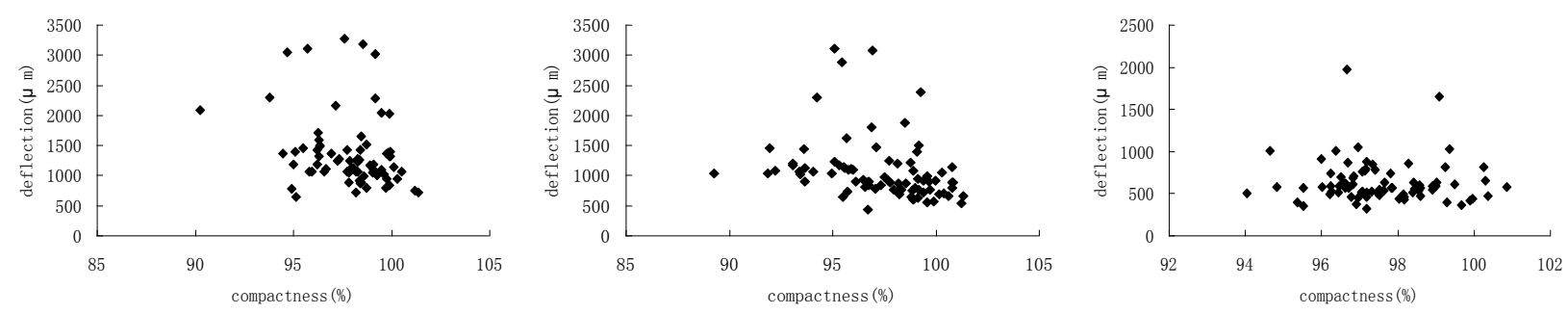

Fig 1 relationship between central deflection and compactness of treated layer, cushion layer and subbase

In fact, compactness only reflects compacted layers' dense state, while the central deflection synthetically expresses the bearing capacity of the tested structure, and they have no good correlation, and it evaluates appropriately the degree of compaction of compacted layer only with the central deflection.

\section{Relationship between load influencing depth and pavement deflection}

Through analyzing the deflection tested by FWD, the pavement structure performance of each layer can represented by deflection basin index or back-calculated modulus(Y. R.et al, 2001), the surface deflection should be consistent with the deformation at a certain depth in pavement structure. Here taking the pavement as a layered elastic system, and using software BISAR3.0, the relationship between load influencing depth and pavement deflection has been analyzed to obtain deformation of compacted layer reflected by which several deflections.

\section{Selection of structure parameters}

Based on the actual project, the model of pavement structure has been established, which is divided into 10 layers, and based on design value, the corresponding material characteristic parameters are set in Tab 1. 
The applied load and acting radius are selected in model, among the vertical load is $50 \mathrm{kN}$, the horizontal load is $0 \mathrm{kN}$, the acting radius is $0.15 \mathrm{~m}, \mathrm{X}$-coordinate and $\mathrm{Y}$-coordinate is 0 , the shear angle is 0 , and the interlayer is fully friction, all the parameters setting are shown in Fig 2.

Tab 1 structure layer parameters

\begin{tabular}{|c|c|c|c|c|}
\hline $\begin{array}{l}\text { Number of } \\
\text { layer }\end{array}$ & Basic parameters & $\begin{array}{l}\text { Elastic modulus } \\
\quad(\mathrm{MPa})\end{array}$ & $\begin{array}{l}\text { Density } \\
\left(\mathrm{Kg} / \mathrm{m}^{3}\right)\end{array}$ & $\begin{array}{l}\text { Poisson ratio } \\
\qquad(\mu)\end{array}$ \\
\hline 1 & $\begin{array}{l}\text { Fine grained type asphalt concrete pavement (AC-13) of } 4 \mathrm{~cm} \\
\text { thickness }\end{array}$ & 2000 & 2400 & 0.25 \\
\hline 2 & $\begin{array}{l}\text { Medium sized particle asphalt concrete pavement (AC-16) of } \\
\qquad 6 \mathrm{~cm} \text { thickness }\end{array}$ & 1800 & 2400 & 0.25 \\
\hline 3 & $\begin{array}{l}\text { Coarse grained type asphalt concrete pavement (AC-25) of } \\
\qquad 8 \mathrm{~cm} \text { thickness }\end{array}$ & 1400 & 2400 & 0.25 \\
\hline 4 & Cement stabilized macadam base of $19 \mathrm{~cm}$ thickness (up ) & 2500 & 2390 & 0.25 \\
\hline 5 & Cement stabilized macadam base of $19 \mathrm{~cm}$ thickness (down) & 2500 & 2390 & 0.25 \\
\hline 6 & $12 \%$ cement stabilized soil cushion layer of $20 \mathrm{~cm}$ thickness & 400 & 1840 & 0.3 \\
\hline 7 & $6 \%$ cement stabilized soil subbase of $20 \mathrm{~cm}$ thickness & 150 & 1790 & 0.3 \\
\hline 8 & $4 \%$ cement-soil processing layer of $20 \mathrm{~cm}$ thickness (up) & 90 & 1790 & 0.35 \\
\hline 9 & $4 \%$ cement-soil processing layer of $20 \mathrm{~cm}$ thickness (down) & 90 & 1880 & 0.35 \\
\hline 10 & Infinite subgrade & 40 & 1740 & 0.35 \\
\hline
\end{tabular}
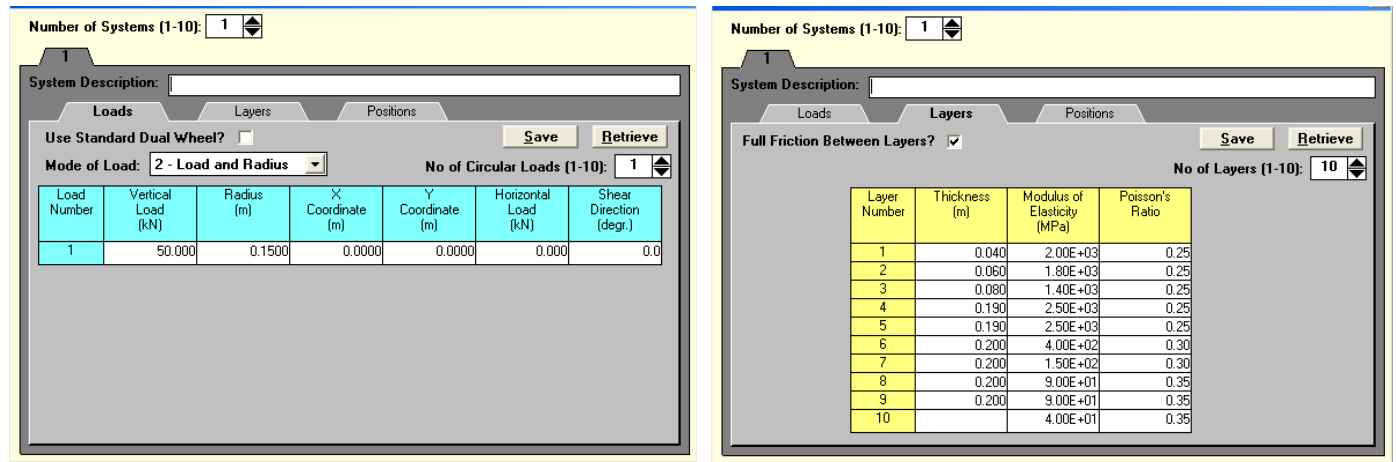

Fig 2 parameter setting of load and structure layers

\section{Relationship between deflection and deformation of structure layer depth}

According to the structure layer parameters and the applied load above, the top deflection under load centre of each layer along the depth direction is calculated, whose relational curve is shown in Fig 3. It can be seen that there is good correlation between deflection and deformation of structure layer depth, and the deflection decreases and tends to be stable with the increase of depth and distance from the load centre.

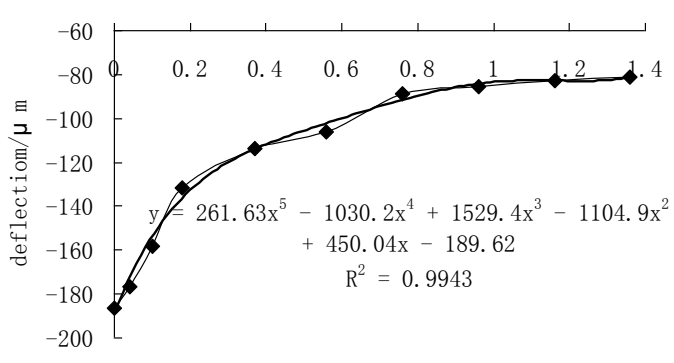

depth from pavement/m

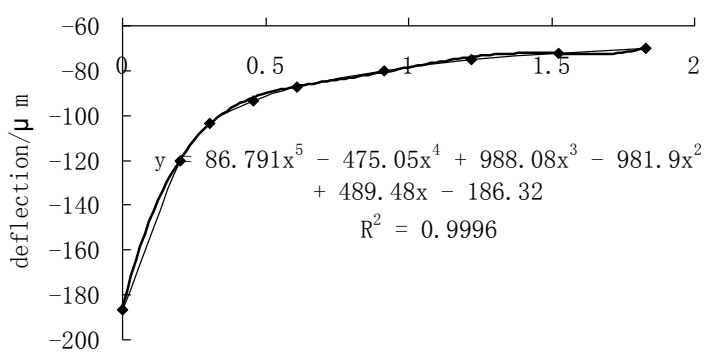

distance from load center/m

Figure 3 curve of deflection along depth from pavement

Fig 4 curve of calculated pavement deflection basin 


\section{Relationship between deflection and deformation of structure layer depth}

According to the structure layer parameters and the applied load above, the top deflection under load centre of each layer along the depth direction is calculated, whose relational curve is shown in Fig 3. It can be seen that there is good correlation between deflection and deformation of structure layer depth, and the deflection decreases and tends to be stable with the increase of depth and distance from the load centre.

\section{Relationship between deflection and deformation of position from load centre}

Similarly, according to structure layer parameters and applied load above, the corresponding deflections at FWD sensors position are calculated, whose deflection basin curve is shown in Fig 4.

Through analyzing the deflections and stresses, strains and displacements at different positions of FWD sensors, it can be seen that the response of three closest deflections from the load plate centre basically has the same order of magnitude. So the loaded upper structure condition of pavement can be reflected by the three closest deflections from the load centre.

\section{Relationship between structure layer depth and distance from load centre}

Based on the deflection equal principle, according to the above calculation results, the relation curve of structure layer depth and distance from load centre is established, and its corresponding curve is shown in Fig 5.

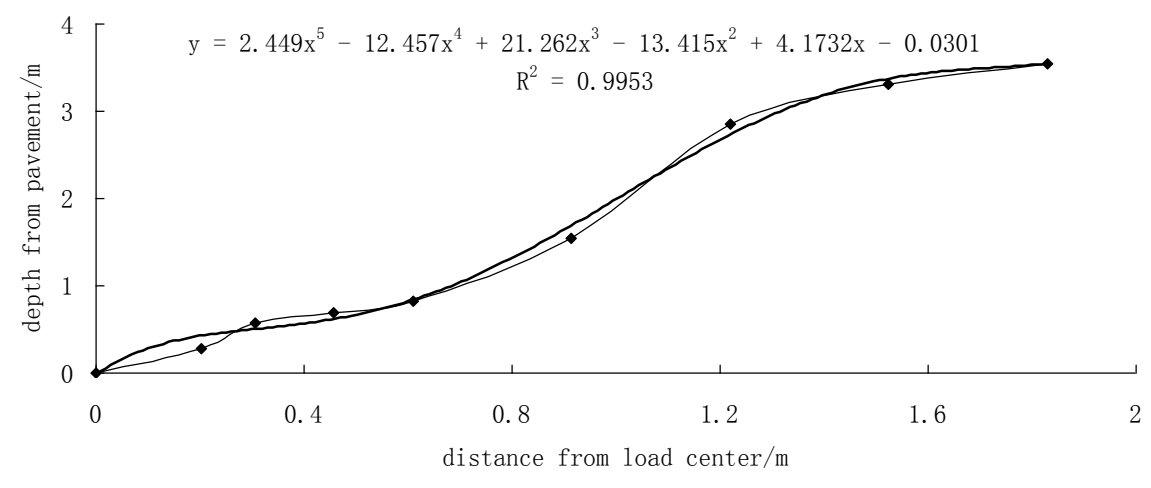

Fig 5 curve of depth from pavement and distance from load center under equal deflection rule

As displayed in Fig 5, the deflection of structure layer depth and distance from the load centre has good correlation. The result shows that the deflection at the second sensor position is equal to that of $0.280 \mathrm{~m}$ depth from pavement surface, so the two deflections from the nearest load centre can be used to reflect the structural condition of compacted layer whose thickness is no more than $30 \mathrm{~cm}$.

Hence, the correlation between compactness of compacted layer and the former three deflections has tried to establish, and the deflection basin index has tried to evaluate the dense state of compacted layer.

\section{Relationship of compactness and deflection basin index}

In accordance with tested deflection and compactness, the correlation between each layer compactness and deflection basin index is analyzed. The actual construction sequence from the bottom up in turn are the cement-stabilized soil, cushion layer and subbase, whose theoretical deflections under standard load are shown in Tab 2. 
Tab 2 calculated deflection basin of each layer

\begin{tabular}{cccccc}
\hline Distance from load & Deflection & Stabilized layer & Cushion layer & Subbase & Base deflection \\
\hline 0.000 & $\mathrm{D}_{1}$ & 2613.0 & 1985.0 & 1181.0 & 408.2 \\
0.203 & $\mathrm{D}_{2}$ & 1336.0 & 1127.0 & 819.5 & 353.9 \\
0.305 & $\mathrm{D}_{3}$ & 987.5 & 863.9 & 685.4 & 334.7 \\
0.457 & $\mathrm{D}_{4}$ & 734.5 & 658.6 & 558.8 & 313.6 \\
0.610 & $\mathrm{D}_{5}$ & 579.2 & 534.4 & 471.7 & 294.6 \\
0.914 & $\mathrm{D}_{6}$ & 394.6 & 385.0 & 358.1 & 260.2 \\
1.219 & $\mathrm{D}_{7}$ & 292.7 & 294.8 & 284.9 & 230.0 \\
1.524 & $\mathrm{D}_{8}$ & 231.3 & 235.6 & 233.6 & 203.9 \\
1.829 & $\mathrm{D}_{9}$ & 191.3 & 194.9 & 196.1 & 181.3 \\
\hline
\end{tabular}

\section{Correlation between compactness of cement-stabilized layer and deflection basin index}

The field measured deflection basin and compactness of cement-stabilized layer are shown in Tab 3, and the regressive curve between calculated deflection basin indexs and actual compactness are shown from Fig 6 to Fig 7. So for the cement-stabilized layer, the deflection basin indexes such as $\left(2 D_{1}+D_{2}\right) / 3 D_{1},\left(D_{1}+D_{2}\right) /\left(D_{2}+D_{3}\right)$ and $\left(D_{1}-D_{3}\right) / D_{2}$ have good correlation with compactness, while the others which are shown in Tab 4 have little correlation with compactness.

Tab 3 deflection basin of different sites on treated layer

\begin{tabular}{cccccccccccc}
\hline Location & Compactness & $\mathrm{D}_{1}$ & $\mathrm{D}_{2}$ & $\mathrm{D}_{3}$ & $\mathrm{D}_{4}$ & $\mathrm{D}_{5}$ & $\mathrm{D}_{6}$ & $\mathrm{D}_{7}$ & $\mathrm{D}_{8}$ & $\mathrm{D}_{9}$ \\
& $(\%)$ & 0.000 & 0.203 & 0.305 & 0.457 & 0.610 & 0.914 & 1.219 & 1.524 & 1.829 \\
\hline K9+920 & 95.10 & 1402.3 & 853.3 & 634.2 & 462.4 & 340.0 & 224.4 & 161.8 & 127.7 & 101.5 \\
K9+925 & 96.19 & 1431.6 & 783.4 & 576.1 & 439.6 & 335.0 & 226.4 & 163.5 & 123.7 & 96.5 \\
K9+930 & 96.29 & 1590.2 & 911.0 & 614.2 & 412.4 & 298.7 & 193.6 & 161.8 & 120.9 & 89.1 \\
K9+960 & 96.56 & 1068.3 & 571.8 & 421.9 & 316.8 & 228.0 & 157.9 & 116.5 & 97.4 & 78.5 \\
K9+950 & 96.95 & 1359.9 & 724.9 & 488.2 & 375.2 & 278.7 & 186.5 & 135.9 & 107.2 & 87.8 \\
K10+050 & 98.20 & 1066.9 & 524.9 & 325.6 & 226.7 & 167.6 & 117.3 & 97.1 & 66.1 & 53.3 \\
K10+055 & 98.36 & 922.0 & 394.7 & 308.3 & 220.9 & 158.8 & 99.2 & 74.5 & 55.9 & 46.5 \\
K10+080 & 99.05 & 1055.3 & 489.7 & 300.6 & 215.3 & 157.1 & 104.8 & 76.2 & 60.9 & 48.8 \\
K10+060 & 99.60 & 1025.6 & 471.0 & 310.9 & 211.4 & 151.8 & 100.7 & 82.4 & 64.1 & 50.2 \\
K10+020 & 99.72 & 791.0 & 352.7 & 250.7 & 174.9 & 120.1 & 80.6 & 67.6 & 53.0 & 44.3 \\
K10+040 & 99.86 & 1385.8 & 650.3 & 396.2 & 234.8 & 152.0 & 94.1 & 71.8 & 58.1 & 49.1 \\
K9+940 & 99.89 & 1320.6 & 561.7 & 421.2 & 316.0 & 232.9 & 156.4 & 132.7 & 96.7 & 79.0 \\
\hline
\end{tabular}
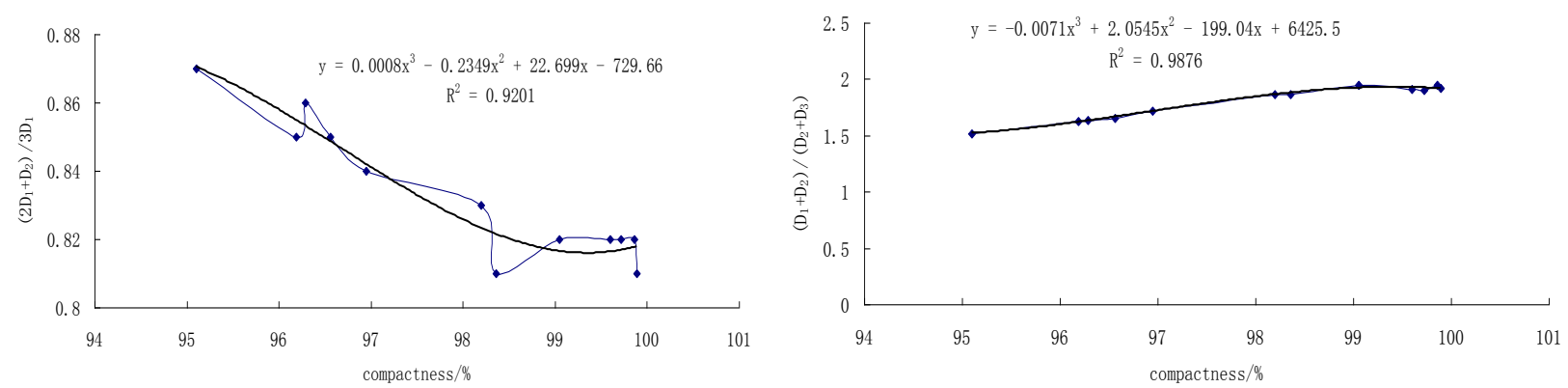

Fig 6 curve of deflection basin index $\left(2 \mathrm{D}_{1}+\mathrm{D}_{2}\right) / 3 \mathrm{D}_{1},\left(\mathrm{D}_{1}+\mathrm{D}_{2}\right) /\left(\mathrm{D}_{2}+\mathrm{D}_{3}\right)$ of treated layer and compactness 


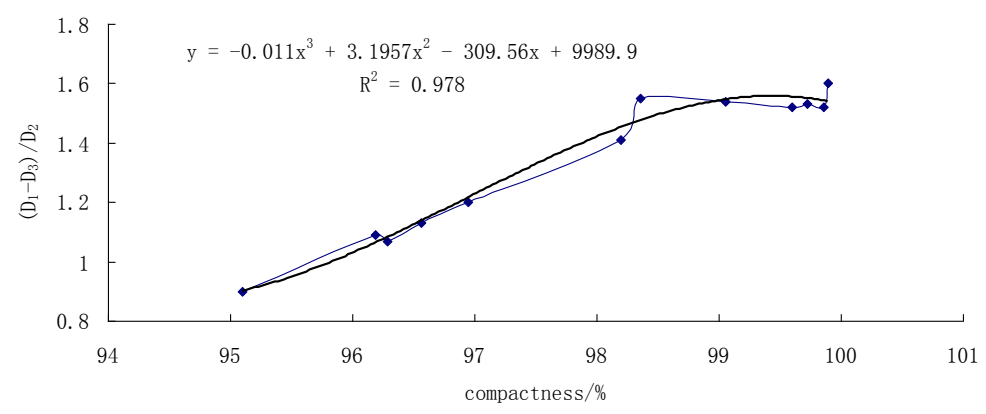

Fig 7 curve of deflection basin index $\left(\mathrm{D}_{1}-\mathrm{D}_{3}\right) / \mathrm{D}_{2}$ of treated layer and compactness

\section{Correlation between compactness of cushion layer and deflection basin index}

Similarly, from the field measured deflection basin of cushion layer, the corresponding deflection basin indexes are calculated, and the curve between calculated deflection basin indexes and compactness are shown in from Fig 8 to Fig 9.
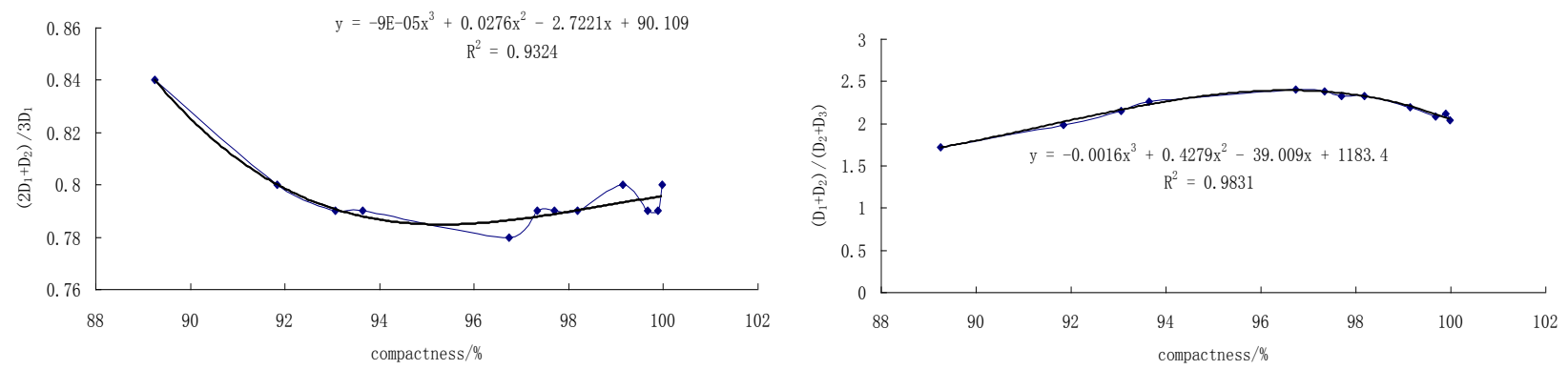

Fig 8 curve of deflection basin index $\left(2 D_{1}+D_{2}\right) / 3 D_{1},\left(D_{1}+D_{2}\right) /\left(D_{2}+D_{3}\right)$ of cushion layer and compactness

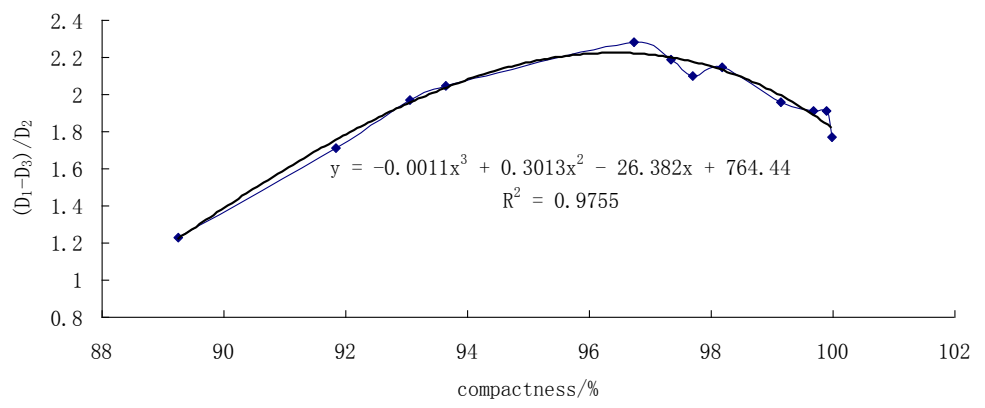

Fig 9 curve of deflection basin index $\left(\mathrm{D}_{1}-\mathrm{D}_{3}\right) / \mathrm{D}_{2}$ of cushion layer and compactness

So for the cushion layer, the deflection basin indexes such as $\left(2 \mathrm{D}_{1}+\mathrm{D}_{2}\right) / 3 \mathrm{D}_{1}$, $\left(\mathrm{D}_{1}+\mathrm{D}_{2}\right) /\left(\mathrm{D}_{2}+\mathrm{D}_{3}\right)$ and $\left(\mathrm{D}_{1}-\mathrm{D}_{3}\right) / \mathrm{D}_{2}$ also have good correlation with compactness, while the other deflection basin indexes have little correlation.

\section{Correlation between compactness of subbase and deflection basin index}

Further, from the field measured deflection basin and compactness of subbase, the calculated deflection basin indexes are calculated, and the correlation between calculated deflection basin indexes and compactness are shown from Fig 10 to Fig 11. So for the subbase, the deflection basin indexes such as $\left(2 \mathrm{D}_{1}+\mathrm{D}_{2}\right) / 3 \mathrm{D}_{1},\left(\mathrm{D}_{1}+\mathrm{D}_{2}\right) /\left(\mathrm{D}_{2}+\mathrm{D}_{3}\right)$ and $\left(\mathrm{D}_{1}-\mathrm{D}_{3}\right) / \mathrm{D}_{2}$ also have good correlation with compactness, while others have little correlation. 

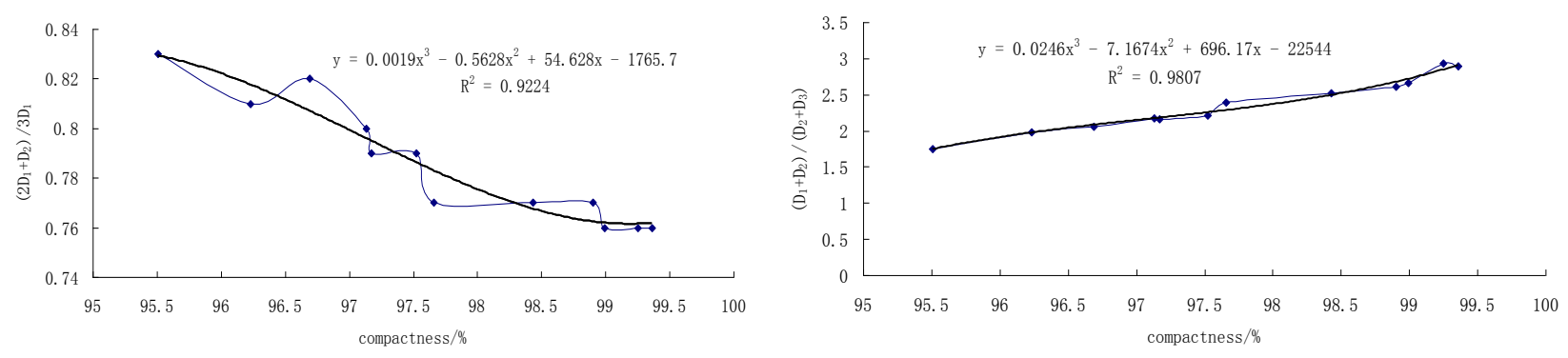

Fig 10 curve of deflection basin index $\left(D_{1}+D_{2}\right) / 3 D_{1},\left(D_{1}+D_{2}\right) /\left(D_{2}+D_{3}\right)$ of subbase and compactness

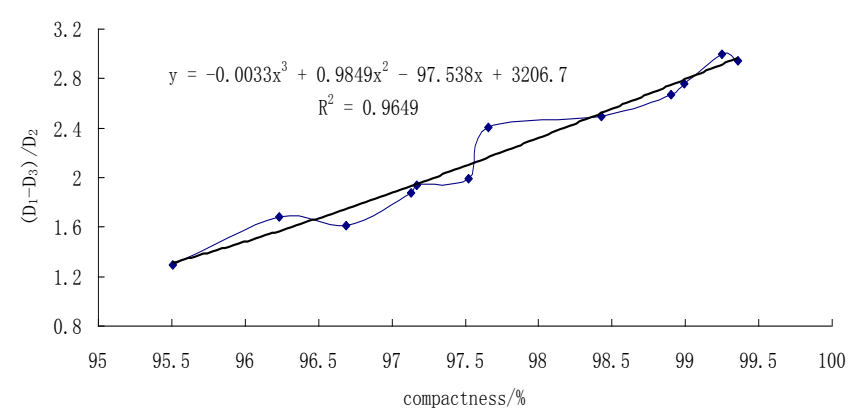

Fig 11 curve of deflection basin index $\left(D_{1}-D_{3}\right) / D_{2}$ of

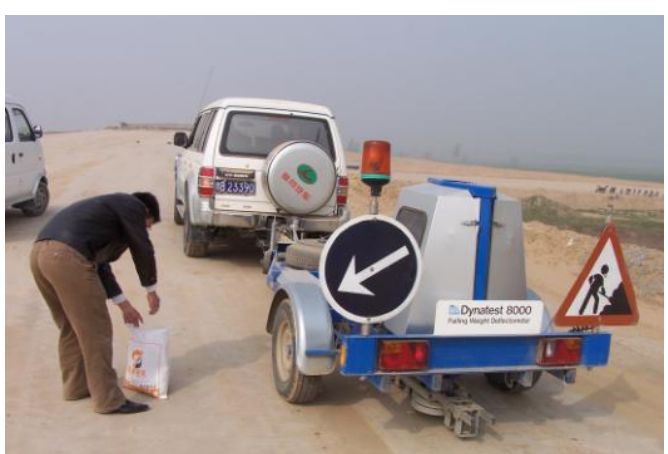

Fig 12 photo of site test on subbase by FWD

subbase and compactness

Through analyzing the above correlation, there is good relationship between the deflection basin index which calculated by the three deflections that is the nearest from the bearing plate and compactness of each layer. Among them, $(2 \mathrm{D} 1+\mathrm{D} 2) / 3 \mathrm{D}_{1},\left(\mathrm{D}_{1}+\mathrm{D}_{2}\right) /\left(\mathrm{D}_{2}+\mathrm{D}_{3}\right)$ and $\left(\mathrm{D}_{1}-\mathrm{D}_{3}\right) / \mathrm{D}_{2}$ have good correlation with compactness for cement-stabilized layer, cushion layer and subbase. By comparing, $\left(D_{1}+D_{2}\right) /\left(D_{2}+D_{3}\right)$ is taken as evaluation index for compactness control.

\section{Case study of compactness control for cushion layer}

Taking an actual cushion layer as an example, whose designed compacted thickness is $20 \mathrm{~cm}$, and the site test photo of FWD is shown in Fig 12. The $\left(D_{1}+D_{2}\right) /\left(D_{2}+D_{3}\right)$ is calculated from tested deflection basins, and according to the correlation between compactness and deflection basin index above, the compactness of test points can be calculated, and the errors between the calculated compactness and measured compactness of corresponding points are shown in Tab 4. As can be seen from Tab 4 , the difference between the obtained compaction based on $\left(D_{1}+D_{2}\right) /\left(D_{2}+D_{3}\right)$ correlation and the measured on site is very small, so the deflection basin index can be used to represent the compactness of cushion layer.

Tab 4 deflection basin indexes and calculated compactness of selected sites on cushion layer

\begin{tabular}{|c|c|c|c|c|c|c|c|c|c|}
\hline$(\mathrm{D} 1+\mathrm{D} 2) /(\mathrm{D} 2+\mathrm{D} 3)$ & 1.28 & 2.33 & 2.46 & 2.28 & 2.75 & 1.83 & 2.98 & 2.78 & 1.67 \\
\hline Calculated compactness $(\%)$ & 94.8 & 97.8 & 98.3 & 97.6 & 99.1 & 95.8 & 99.3 & 99.2 & 95.3 \\
\hline Measured compactness $(\%)$ & 95.1 & 97.7 & 98.2 & 97.1 & 99.1 & 95.5 & 99.2 & 98.8 & 95.1 \\
\hline Error $(\%)$ & -0.3 & 0.1 & 0.1 & 0.5 & 0 & 0.3 & 0.1 & 0.4 & 0.2 \\
\hline
\end{tabular}




\section{Case study of compactness control for subbase}

When constructing the subbase, whose designed compacted thickness is also $20 \mathrm{~cm}$, The deflection basin index $\left(D_{1}+D_{2}\right) /\left(D_{2}+D_{3}\right)$ and calculated compactness and measured compactness of corresponding test points and the errors are shown in Tab 5. It can be seen that the difference between the calculated compactness and the measured on site is very small, so the deflection basin index can be used to represent the compactness of subbase.

Tab 5 comparison between calculated and measured compactness of selected sites on subbase
\begin{tabular}{cccccccccccc} 
(D1+D2)/(D2+D3) & 1.48 & 1.95 & 2.04 & 2.18 & 2.14 & 2.19 & 2.35 & 2.69 & 3.01 \\
\hline & & & & & & & & & \\
\hline Calculated compactness $(\%)$ & 94.9 & 96.5 & 96.9 & 97.4 & 97.2 & 97.4 & 97.9 & 99.1 & 100.2 \\
Measured compactness $(\%)$ & 95.4 & 96.6 & 96.6 & 97.1 & 97.3 & 97.6 & 98.4 & 98.5 & 99.1 \\
Error (\%) & -0.5 & 0.0 & 0.3 & 0.3 & -0.1 & -0.2 & -0.5 & 0.6 & 1.2 \\
\hline
\end{tabular}

\section{Conclusion}

Based on the deflection detected by FWD, combining with the field tests, and analyzing the pavement structure, the three deflections from the nearest load centre is found to reflect the structural condition of compacted layer.

The deflection basin index has good correlation with compactness, so during rolling compaction process, the $\left(D_{1}+D_{2}\right) /\left(D_{2}+D_{3}\right)$ can be taken as evaluation index to directly control compaction quality.

\section{References}

[1] Guo Chengchao, Wang Peng(2008), Application study on travelling deflerctometer rapid testing subgrade compaction, Subgrade Engineering,6,131-132.(in Chinese).

[2] Joe Grobler, Cameron Taylor(2011), The use of FWD testing as a quality control tool during construction, AAPA 14th International Flexible Pavements Conference.

[3] Wang Peng, Guo Chengchao (2009), The Application of PFWD in Sub-Grade Compactness Test, 2009 GeoHunan International Conference, GSP,194, 84-91. (in Chinese).

[4] Wang Peng, Guo Chengchao, Wang Haitao(2007), Experimental Research for Subgrade Compactness Effect of Increased Compaction Energy, Journal of Highway and Transportation Research and Development, 24(2), 1-4. (in Chinese).

[5] Yoshio Tatsumi, Osamu Takahashi(2007), Strength evaluation for subgrade and subbase using historocal time data of portable FWD, Journal of the Eastern Asia Society for Transportation Studies, Vol. 7,2131-2143.

[6] Y. R. Kim et al (2001), Assessing Pavement Layer Condition Using Deflection Data, NCHRP $10-48$.

[7] Zhang Bei, Wang Haitao, Wang Fuming (2007), Testing and research on maximum dry density attenuating mechanis m of lime- stabilized soil, Subgrade Engineering, 6, 95-96. (in Chinese 
